\title{
Burnout among Lebanese nurses: Psychometric properties of the Maslach Burnout Inventory-Human Services Survey (MBI-HSS)
}

\author{
Ibtissam Sabbah ${ }^{1}$, Hala Sabbah ${ }^{2}$, Sanaa Sabbah $^{3}$, Hussein Akoum $^{1}$, Nabil Droubi $^{{ }^{*}}$ \\ ${ }^{1}$ Faculty of Public Health, Lebanese University, Saida, Lebanon; ${ }^{*}$ Corresponding Author: nsdroubi@inco.com.lb \\ ${ }^{2}$ Faculty of Economic Sciences and Business Administration, Lebanese University, Nabatieh, Lebanon \\ ${ }^{3}$ Doctoral School of Literature, Humanities \& Social Sciences, Institute of Social Science, Lebanese University, Saida, Lebanon
}

Received 28 May 2012; revised 25 June 2012; accepted 3 July 2012

\section{ABSTRACT}

Background: Burnout is a mental condition defined as a result of continuous and long-term stress exposure, particularly related to psychosocial factors at work. This paper aims to examine the psychometric properties of the Maslach Burnout Questionnaire (MBI-HSS) for validation of use in Lebanon, and to describe burnout and associated factors amongst nurses in Lebanon especially the gender and employment sector. Methods: The psychometric properties of the Arabic version of MBI-HSS were studied amongst a sample of 200 nurses. In this descriptive study, survey data were collected from private and public hospitals. The data were analyzed by means of descriptive statistics and multivariate analysis. Results: The results indicated satisfactory reliability through internal consistency for all three scales of the MBI-HSS. The factor analysis was quite satisfactory. Most of staff had scores which indicated they were burnt out. Nearly three quarters $(\mathbf{7 7 . 5 \% )}$ reported emotional exhaustion, $36.0 \%$ reported depersonalization while almost one third (33.0\%) experienced reduced personal accomplishment. Burnout increases for $\mathbf{3 0}$ - 39 years age groups. Married nurses had significantly higher emotional exhaustion. Depersonalization was highest among nurses in private sector, and personal accomplishment was highest among nurses in public sector. Depersonalization proved to be higher in night and rotating shift nurses. Depression, backache, and headache were predictors of burnout. Conclusion: Findings indicate that the main psychometric properties of reliability and validity of the Arabic version of MBI-HSS appear to be satisfactory. Burnout is particularly prominent and severe in the nurses working population. The implications of these findings for interventions that reduce burnout and promote nursing mental health are therefore in the interest of employers, governments and policy makers.

Keywords: Burnout; Maslach; Psychometrics Properties; Nurses

\section{INTRODUCTION}

Nursing is a stressful profession that deals with human aspects of health and illness [1-3], and can ultimately lead to job dissatisfaction and burnout

Burnout is a mental condition defined as the body's response to the failure of the coping strategies that individuals typically utilize to manage stress at work [4-6]. The accumulation of stress exhausts individuals to the point where their energy resources are insufficient for their attempts to overcome the pressure of a situation in which they work with other people [7-10]. The worker loses the interest and positive sentiments that he/she had for individuals assisted and develops a negative selfimage $[11,12]$.

The notion of professional burnout was first introduced by Freudenberger, to describe overload symptoms that he observed among volunteers treating drug addiction patients [10]. The most widely accepted definition of burnout was formulated by Maslach [3,12] who described it as a psychological syndrome of emotional exhaustion, depersonalization and reduced personal accomplishment, that develops in people who have a professional relationship with other persons. Faber [13] proposed differentiation of the syndrome based on the description of three clinical profiles: "frenetic" (works increasingly harder until he or she is exhausted and seeks satisfaction or success to balance the stress caused by the invested efforts), "underchallenged" (presented with in- 
sufficient motivation and must therefore cope with monotonous and unstimulating work conditions that do not provide necessary satisfaction) and "worn-out" (gives up when faced with too much stress or very little gratification at work).

Burnout is a variable that continues to sustain international research interest. It is becoming a growing phenomenon in the workplace especially in health sector with decreased well-being of caregiving staff $[10,14]$. It has been associated with negative workplace behaviors such as absenteeism, sick leaves, premature retirement low morale, alcohol abuse, increases in smoking and coffee consumption, and workplace accidents [3,7,15-17]. It can also lead to deterioration in the quality of care or service provided by the staff posing a threat to the healthcare systems [3]. It is highly probable that nursing burnout, unless handled appropriately, will reduce healthcare standards internationally [18].

Job satisfaction and burnout have been studied in several industrial countries, but remain poorly researched in the Arab culture and the majority of the work remains unpublished $[1,19]$. The most widely adopted tool measuring the burnout syndrome is the Maslach Burnout Inventory (MBI) [7,8,16,20,21]. It has been translated into several languages. The original measure of the instrument that was designed for professionals in the human services (MBI-Human Services Survey or MBI-HSS). The questionnaire must be adapted to the population before being administered. The recent research has introduced the necessity of establishing international norms of the MBI-HSS as well as specific occupations normssuch nursing - for each of their three subscales. The rate of burnout among nurses and its effect on their lives have been previously investigated by many researchers $[1,14$, 19,20,22-29]. The aim of this study is 1) to examine the psychometric properties of the MBI-HSS; and 2) attempt to assess the associations between selected individual, work characteristics, (especially the gender and Employment sector), morbidity and burnout amongst nurses in Lebanon.

\section{METHODS}

Maslach Burnout study was conducted in 7 hospitals in South Lebanon between February 1 and April 30, 2011. A random sample of one thousand nurses from hospitals was selected, taken into account all job degrees of nurses. Ethical permission to conduct the study was obtained from hospitals directors prior to data collection. An informed consent was obtained from those who agreed to complete the questionnaire. The inclusion criteria were 1) 18 years of age and older; 2) ability to speak and read Arabic; and 3) being a registered nurse or nurse, working in the public or private sector.

In this descriptive study, burnout variables were stud- ied with the Arabic version of MBI-HSS [3,12], which comprises 22 items regrouped into 3 subscales: emotional exhaustion (EE; nine items), depersonalization (DP; five items), and personal accomplishment (PA; eight items). Each item can be answered on a 7-point Likert scale ranging from "never" (=0) to "daily" $(=6)$. The results of this inventory consist of three separate scores, one for each factor. A combination of high scores on EE and DP, and a low score on PA, correspond to a high level of burnout. At present, scores are considered high if they are in upper third of normative distribution, middle if they are in the middle third and low if they are in the lower third [12]. The MBI-HSS is a self administered questionnaire, has been reliable and valid, easy to administer, and takes 10 - 15 minutes to fill out.

Respondents were advised to fill in the self-report forms alone during the shifts. The forms were collected by the interviewer who carefully examined each completed test form to make sure all items had been answered, and to ask the respondents immediately about unanswered items. The missing items were noted before completion to evaluate the face validity of the questionnaire later. Respondents completed a questionnaire that included socio-demographic, professional variables, workrelated factors, habitation (urban vs. rural), cigarette smoking, leisure physical activities, and self evaluation of their health and quality of life. Self-reported diseases and symptoms, employing a recall period of 12 months, and the use of antalgic, anxiolytics or sleepping pills were also collected. Job outcome variables were measured with two single-item questions: nurse satisfaction with the current job (very dissatisfied, dissatisfied, satisfied, very satisfied) and intention to leave work in current institution in the next 12 months (yes, no, I don't know). All values were coded, so that higher values indicated stronger agreement or more favorable ratings.

\subsection{Validity Assessment}

The psychometric characteristics of the Arabic-language version of the MBI-HSS were examined.

The mean and standard deviation (SD) for responses to each item and scale were calculated. The percentage of people with scores at the ceiling (percentage of subjects with a score of 100) and floor (lowest level) were calculated for each scale.

The acceptability was tested by studying the percentage of refusals, the percentage of missing items, and the percentage of complete questionnaires [30].

Reliability was assessed by tests of internal consistency using Cronbach's $\alpha$ coefficient [3,30,31]. Scales with reliabilities of 0.70 or greater are recommended for comparing patient groups, while a reliability criterion of 0.90 is recommended for analyzing individual patient scale scores [3,30,31]. 
Principal component analysis with varimax rotation was carried out on correlation among scales to compare the factorial structure of data with that obtained from the original instrument. The authors distinguish three situations: the average score from a scale is substantially correlated if factor loading is greater than 0.7 , moderately correlated if factor loading is between 0.3 and 0.7 , and slightly correlated if factor loading is less than $0.3[3,31]$. "Known groups" validity is a form of construct validity that measures the ability of an instrument to discriminate between groups of subjects who differ according to a relevant variable. Both convergent and discriminant validity can be tested $[3,30]$. The validity of known groups was computed by making the association between the sociodemographic parameters, professional and work environment, and declared morbidity.

\subsection{Burnout According to Gender and Hospital Status}

The validity of known groups makes it possible to evaluate at the same time the burnout according to hospital status (i.e. private vs. public), gender (i.e. male vs. female. Our hypothesis was: the female nurse, working in a public hospital will be more exposed to stressful situations and consequently, more susceptible to burnout. The independent sample t-test and one way analysis of variance (ANOVA) were used to assess whether the means of two groups were statistically different from each other. The chi-square test was used to explore the existence of a statistically significant relationship between the categorical variables.

A multivariate analysis was performed to test the effect of gender and hospital status on all domains of the MBI-HSS. The equation included the three subscales (EE, PA, DP) overall score as dependent variable. The adjustments were performed by generalized linear model. Because of multiple testing, $\mathrm{P}$ values $<0.01$ were considered to be significant. All data were recorded, and tabulated for analysis using the SPSS 16.0 for Windows statistical package.

\section{RESULTS}

\subsection{Nurse's Characteristics}

Of the 210 selected Lebanese nurses, 200 (95.2\%) agreed to participate in this study (31.5\% males). No questionnaire was excluded because of missing data. The mean age was $30.01(\mathrm{SD}=6.62)$ years, with approximately $87.5 \%$ being younger than 40 years. The mean years of professional experience in the current setting was $6.67(\mathrm{SD}=6.01)$ years, women have worked for several years more than men $(7.3 \pm 6.0$ and $5.4 \pm 6.7$ years, respectively; $\mathrm{P}=0.04$ ). In this sample $90.5 \%$ were
Lebanese. The majority of respondents $(66.5 \%)$ worked as Registered Nurses (RN), $84 \%$ of respondents had a university level and higher. About one third of nurses $(30 \%)$ have a turnover. The mean of income was 1,036,000 $(\mathrm{SD}=268,000$; median $=1,200,000)$ Lebanese Pounds. Nearly all nurses were working fulltime (98.5\%). About half of nurses $(42.5 \%)$ reported that they did have overtime working hours. $34.50 \%$ were current smokers. Regarding the perception of health status, 39.7\% reported fair and less (very poor and poor) status. Concerning satisfaction at work, $12.6 \%$ reported very poor and poor satisfaction, $16.6 \%$ decide, and $42.7 \%$ hesitant to leave work in the next 12 months (Table 1). Backache $(54.0 \%)$ and insomnia $(37.5 \%)$ were the predominant self-reported symptom, whereas depression was reported by $20.5 \%$ of the study participants (Table 2 ). $36.2 \%$ were overweight, and $8.0 \%$ were obese.

\subsection{Psychometric Properties of the MBI-HSS}

Table 3 displays the mean and standard deviations of the results of each of the three subscales of the MBI-HSS. The mean scores for each subscale of the MBI-HSS reflect in principle the average level of burnout of the population studied. The floor and ceiling effect is very small ranged from $0 \%$ to $4.5 \%$ for all subscales of the MBI (Table 3).

For each dimension, the Cronbach's alpha is always greater than 0.70 . The matrix of correlations between MBI-HSS scales scores shows significant positive relationships between emotional exhaustion and depersonalization, and significant negative relationships between PA, EE, and DP (Table 4). These results are in line with the psychometric properties of the original MBI [3], and indicate that all dimensions converge on the same construct.

Factor analysis of the 22 items of MBI-HSS yielded a three-factor solution corresponding to the hypothesized EE, DP and PA scales of Maslach burnout. Table 5 shows the 13th item of EE (I feel frustrated by my job) loading most on the "DP" component and least on the "EE". Also, the 22th item (I feel recipients blame me for some of their problems) had stronger loading on the "EE" component than the "DP" component.

\subsection{Individual, Environmental, and Work Characteristics and Burnout}

In general, nurses in this study reported moderate levels of burnout. They reported mostly high levels of emotional exhaustion (77.5\%), high levels of depersonalization $(36.0 \%)$, and low levels of personal achievement (33.0\%) (Table 3).

In the unadjusted analysis (Tables 1 and 2), each of the 
Table 1. Nurses' characteristics, and mean (SD) of the MBI-HSS subscales scores of Lebanese nurses according to socio-demographic variables, environmental and work variables: one way ANOVA test.

\begin{tabular}{|c|c|c|c|c|}
\hline \multirow{2}{*}{ Total $(n=200)$} & \multirow{2}{*}{ n (\%) } & \multicolumn{3}{|c|}{ Mean (SD) of the MBI-HSS subscales score } \\
\hline & & Emotional exhaustion & Depersonalization & Personal accomplishment \\
\hline \multicolumn{5}{|l|}{ Habitat location } \\
\hline Urban & $94(47.0)$ & $34.2(9.9)$ & $11.1(7.3)$ & $33.8(8.8)$ \\
\hline Rural & $106(53.0)$ & $32.9(11.4)$ & $11.0(7.0)$ & $34.0(8.5)$ \\
\hline \multicolumn{5}{|l|}{ Gender } \\
\hline Male & $63(31.5)$ & $32.8(10.9)$ & $12.27(7.02)$ & $33.4(9.4)$ \\
\hline Female & $137(68.5)$ & $33.9(10.6)$ & $10.47(7.12)$ & $34.1(8.3)$ \\
\hline \multicolumn{5}{|l|}{ Age (years) } \\
\hline $20-29$ & $117(58.5)$ & $32.2(10.4)$ & $10.8(6.9)$ & $32.8(8.7)$ \\
\hline $30-39$ & $58(29.0)$ & $36.5(10.5)$ & $11.4(7.7)$ & $35.4(8.3)$ \\
\hline$\geq 40$ & $25(12.5)$ & $33.0(11.5)^{* * *}$ & $10.9(7.1)$ & $35.4(8.5)$ \\
\hline \multicolumn{5}{|l|}{ Employment sector } \\
\hline Private & $140(70.0)$ & $33.6(10.6)$ & $11.7(7.2)$ & $32.9(9.0)$ \\
\hline Public & $60(30.0)$ & $33.3(11.0)$ & $9.6(6.7)^{* * *}$ & $36.1(7.4)^{* * *}$ \\
\hline \multicolumn{5}{|l|}{ Family status } \\
\hline Single & $92(46.0)$ & $31.7(10.0)$ & $11.0(6.7)$ & $33.6(7.4)$ \\
\hline Married & $102(51.0)$ & $35.4(11.1)$ & $11.0(7.6)$ & $34.3(9.5)$ \\
\hline Divorced & $6(3.0)$ & $29.0(9.4)^{* * *}$ & $11.7(4.5)$ & $30.5(9.8)$ \\
\hline \multicolumn{5}{|l|}{ Job title } \\
\hline Nurse & $41(20.5)$ & $32.4(9.1)$ & $11.8(6.3)$ & $33.7(8.7)$ \\
\hline Registered nurse & $133(66.5)$ & $33.8(11.3)$ & $11.1(7.5)$ & $33.3(8.1)$ \\
\hline Head nurse/supervisor & $26(13.0)$ & $34.0(10.3)$ & $09.5(6.2)$ & $36.9(10.6)$ \\
\hline \multicolumn{5}{|l|}{ Shift duty } \\
\hline Day & $82(41.0)$ & $33.5(10.9)$ & $9.9(6.79)$ & $35.7(8.2)$ \\
\hline Night & $26(13.0)$ & $37.0(9.9)$ & $14.5(7.8)$ & $31.35(7.9)$ \\
\hline Alternant & $92(46.0)$ & $32.6(10.7)$ & $11.0(7.0)^{* * *}$ & $32.9(8.9)^{* * *}$ \\
\hline \multicolumn{5}{|l|}{ Work overload } \\
\hline Yes & $179(90.9)$ & $34.4(10.3)$ & $11.4(7.2)$ & $33.5(8.7)$ \\
\hline No & $18(9.1)$ & $26.0(11.6)^{*}$ & $8.5(6.1)$ & $37.7(7.5)^{* * *}$ \\
\hline \multicolumn{5}{|l|}{ Health status perception } \\
\hline poor & $11(05.5)$ & $40.8(10.3)$ & $16.55(6.7)$ & $29.6(7.4)$ \\
\hline Fair & $68(34.2)$ & $37.7(9.2)$ & $13.65(7.4)$ & $31.3(8.6)$ \\
\hline Good, very good & $120(60.3)$ & $30.3(10.3)^{*}$ & $8.92(6.0)^{*}$ & $35.9(8.1)^{*}$ \\
\hline \multicolumn{5}{|l|}{ Quality of life perception } \\
\hline Very poor \& poor & $4(2.0)$ & $37.2(13.1)$ & $11.2(9.0)$ & $29.8(9.2)$ \\
\hline Intermediate & $83(41.9)$ & $37.3(9.4)$ & $13.6(6.9)$ & $32.0(8.5)$ \\
\hline Good \& very good & $111(56.1)$ & $30.5(10.5)^{*}$ & $9.0(6.5)^{*}$ & $35.6(8.4)^{* *}$ \\
\hline \multicolumn{5}{|l|}{ Satisfaction with work } \\
\hline Very poor \& poor & $25(12.6)$ & $39.4(9.1)$ & $15.6(5.9)$ & $30.0(7.8)$ \\
\hline Intermediate & $78(39.4)$ & $37.42(9.4)$ & $13.1(7.8)$ & $31.9(8.8)$ \\
\hline Good, very good & $95(48.0)$ & $28.8(10.3)^{* *}$ & $8.1(5.6)^{* *}$ & $36.6(7.9)^{* *}$ \\
\hline \multicolumn{5}{|l|}{ Leave work in 12 months } \\
\hline Yes & $33(16.6)$ & $36.2(9.7)$ & $13.9(6.6)$ & $30.4(7.5)$ \\
\hline No & $81(40.7)$ & $32.3(10.7)$ & $9.1(6.2)$ & $36.1(8.0)$ \\
\hline I don't know & $85(42.7)$ & $33.8(11.0)$ & $11.8(7.6)^{* *}$ & $33.1(9.1)^{* *}$ \\
\hline
\end{tabular}

Notes and abbreviations: $\mathrm{n}$ : number of individuals; $\mathrm{SD}=$ standard deviation; ${ }^{*} \mathrm{P}<0.001 ;{ }^{* *} \mathrm{P}<0.01 ;{ }^{* * *} \mathrm{P}<0.05$; blanks in table indicate a non significant $\mathrm{P}$ value for the three subscales in that test. 
Table 2. Description of the 3 subscales scores of the Arabic version of MBI-HSS.

\begin{tabular}{|c|c|c|c|c|c|c|c|c|c|c|c|}
\hline \multirow{2}{*}{ Scale } & \multirow{2}{*}{$\mathbf{k}$} & \multirow{2}{*}{ Mean (SD) } & \multirow{2}{*}{ Min - Max } & \multicolumn{3}{|c|}{ Percentile } & \multicolumn{3}{|c|}{ Categorization of the MBI-HSS } & \multirow{2}{*}{ \% Ceiling } & \multirow{2}{*}{$\%$ Floor } \\
\hline & & & & 25 th & 50th & 75th & Low n (\%) & Moderate n (\%) & High n (\%) & & \\
\hline $\mathbf{E E}$ & 9 & $33.5(10.7)$ & $4-54$ & 27.0 & 34.0 & 41.0 & $15(07.5)$ & $30(15.0)$ & $155(77.5)$ & 1.5 & 0.0 \\
\hline DP & 5 & $11.0(7.1)$ & $0-29$ & 6.0 & 9.0 & 16.8 & $61(30.5)$ & $67(33.5)$ & $72(36.0)$ & 0.0 & 3.0 \\
\hline PA & 8 & $33.9(8.6)$ & $0-48$ & 28.0 & 34.0 & 40.8 & $66(33.0)$ & $51(25.5)$ & $83(41.5)$ & 4.5 & 0.5 \\
\hline
\end{tabular}

Notes and abbreviations: $\mathrm{k}=\#$ of item; $\mathrm{SD}=$ standard deviation; $\min =$ minimum, $\max =\operatorname{maximum} ; \mathrm{n}=$ number of individuals; EE $=$ Emotional exhaustion high $(\geq 31)$, moderate $(21-30)$, low $(\leq 20)$; DP = Depersonalization: high $(\geq 11)$, moderate $(6-10)$, low $(\leq 5)$; PA = Personal accomplishment: high $(\leq 35)$, moderate (41-36), low $(\geq 42)$.

Table 3. Reliability (Cronbach's $\alpha$ ), standard error of measurement (SEM), and interscales correlations matrix of MBI-HSS (Arabic in comparison with the original version [3].)

\begin{tabular}{ccccccc}
\hline & \multicolumn{2}{c}{ Reliability } & & SEM & \multicolumn{2}{c}{ Interscales correlations matrix $^{1}$} \\
\hline & Lebanon & Original version [3] & Lebanon & Original version [3] & EE & DP \\
EE & 0.80 & 0.90 & 4.79 & 3.80 & - & - \\
DP & 0.73 & 0.79 & 3.70 & 3.16 & $0.55(0.52)^{2}$ & - \\
PA & 0.77 & 0.71 & 4.14 & 3.73 & $-0.15(-0.22)^{2}$ & $-0.36(-0.26)^{2}$ \\
\hline
\end{tabular}

Notes and abbreviations: $\mathrm{EE}=$ Emotional exhaustion; $\mathrm{DP}=$ Depersonalization; $\mathrm{PA}=$ Personal accomplishment. ${ }^{1}$ Total variance explained by these 3 factors is $57.67 \%$, Communalities: EE (0.61), DP (0.77), and PA (0.35). P $<0.001$ for all correlations; ${ }^{2}$ Interscales correlations matrix of the original version [3] in parenthesis.

Table 4. Item mean, standard deviation (SD), and rotated principal components ${ }^{1}$ of the MBI-human services survey (MBI-HSS) Scales.

\begin{tabular}{|c|c|c|c|c|c|}
\hline Item & Mean (SD) & $\mathrm{EE}$ & DP & PA & $h^{2}$ \\
\hline 1. I feel emotionally drained from my work. & $3.5(2.0)$ & 0.64 & 0.23 & -0.03 & 0.47 \\
\hline 2. I feel used up at the end of the workday. & $4.2(1.8)$ & 0.70 & 0.10 & -0.25 & 0.56 \\
\hline 3. I feel fatigued when I get up in the morning and have to face another day on the job. & $4.3(1.7)$ & 0.64 & 0.13 & -0.39 & 0.58 \\
\hline 4. I can easily understand how my recipients feel about things. & $4.8(1.5)$ & 0.39 & -0.22 & 0.40 & 0.36 \\
\hline 5. I feel I treat some recipients as if they were impersonal objects. & $1.5(1.8)$ & 0.06 & 0.64 & -0.19 & 0.45 \\
\hline 6. Working with people all day is really a strain for me. & $4.7(1.6)$ & 0.61 & 0.08 & 0.12 & 0.40 \\
\hline 7. I deal very effectively with the problems of my recipients. & $4.8(1.5)$ & 0.42 & -0.20 & 0.55 & 0.52 \\
\hline 8. I feel burned out from my work. & $3.4(2.1)$ & 0.52 & 0.52 & -0.07 & 0.54 \\
\hline 9. I feel I'm positively influencing other people's lives through my work. & $4.6(1.5)$ & 0.33 & -0.18 & 0.49 & 0.38 \\
\hline 10. I've become more callous toward people since I took this job. & $2.2(2.2)$ & 0.08 & 0.79 & -0.20 & 0.67 \\
\hline 11. I worry that this job is hardening me emotionally. & $2.5(2.3)$ & 0.15 & 0.76 & -0.17 & 0.63 \\
\hline 12. I feel very energetic. & $3.8(2.0)$ & -0.37 & -0.21 & 0.57 & 0.51 \\
\hline 13. I feel frustrated by my job. & $2.3(2.2)$ & $\underline{0.32}$ & 0.59 & -0.18 & 0.49 \\
\hline 14. I feel I'm working too hard on my job. & $4.5(1.8)$ & 0.51 & 0.01 & 0.19 & 0.30 \\
\hline 15. I don't really care what happens to some recipients. & $1.5(1.9)$ & -0.01 & 0.72 & -0.13 & 0.53 \\
\hline 16. Working with people directly puts too much stress on me. & $3.0(2.0)$ & 0.42 & 0.42 & -0.09 & 0.37 \\
\hline 17. I can easily create a relaxed atmosphere with my recipients. & $4.7(1.5)$ & 0.17 & -0.31 & 0.64 & 0.54 \\
\hline 18. I feel exhilarated after working closely with my recipients. & $3.8(2.0)$ & -0.11 & -0.14 & 0.68 & 0.50 \\
\hline 19. I have accomplished many worthwhile things in this job. & $3.8(1.9)$ & -0.14 & -0.03 & 0.78 & 0.63 \\
\hline 20. I feel like I'm at the end of my rope. & $3.6(2.0)$ & 0.40 & 0.37 & 0.07 & 0.30 \\
\hline 21. In my work, I deal with emotional problems very calmly. & $3.7(2.0)$ & 0.04 & -0.03 & 0.55 & 0.31 \\
\hline 22. I feel recipients blame me for some of their problems. & $3.3(2.0)$ & 0.38 & $\underline{0.26}$ & 0.17 & 0.24 \\
\hline
\end{tabular}

Notes and abbreviations: ${ }^{1}$ correlation between each item and rotated principal component. Items belonging to the postulated scales are shown by bold numbers. Factor loadings under 0.4 have been underlined. The percentage of measured variance explained by these three factors is $46.72 \%$ : The first component explains $15.92 \%$, second $(15.82 \%)$, and the third $(14.98 \%) ; \mathrm{h}^{2}$ (communalities): proportion of total variance of each item explained by four extracted components. Strong association $(\mathrm{r}>0.70)$; moderate association $(0.30<\mathrm{r}<0.70)$; weak association $(\mathrm{r}<0.30)$; EE $=$ Emotional exhaustion; DP $=$ Depersonalization; PA $=$ Personal accomplishment. 
Table 5. Relationship between health problems, lifestyle, and the mean (SD) MBI-HSS subscale scores: independent samples t-test.

\begin{tabular}{lcccc}
\hline \multirow{2}{*}{$\mathbf{N}=\mathbf{2 0 0}$} & $\mathbf{n}(\%)$ & \multicolumn{3}{c}{ Mean (SD) of the MBI-HSS subscales score } \\
\cline { 3 - 5 } & & Emotional exhaustion & Depersonalization & Personal accomplishment \\
\hline Headache & $57(28.5)$ & $37.9(9.7)^{*}$ & $15.2(7.4)^{*}$ & $31.8(8.8)^{* * * *}$ \\
Backache & $108(54.0)$ & $37.4(9.7)^{*}$ & $12.6(7.5)^{*}$ & $33.14(9.1)$ \\
Depression & $41(20.5)$ & $40.6(9.4)^{*}$ & $15.2(7.6)^{*}$ & $32.3(9.2)$ \\
Insomnia & $57(37.5)$ & $37.4(9.4)^{*}$ & $12.8(7.5)^{* *}$ & $32.8(8.6)$ \\
Hypertension & $10(5.0)$ & $38.6(10.0)$ & $14.3(7.0)$ & $29.9(13.4)$ \\
Anxiolytics/sleeping pills & $63(31.50)$ & $37.7(10.0)^{*}$ & $13.8(7.5)^{*}$ & $30.6(7.8)^{*}$ \\
Antalgic use & $44(22.0)$ & $34.8(10.1)^{*}$ & $11.3(7.2)$ & $33.7(8.7)$ \\
Smoking & $69(34.50)$ & $34.5(10.4)$ & $12.2(6.9)$ & $32.6(8.4)$ \\
Physical activity (leisure) & & $31.2(10.8)^{* * *}$ & $9.3(6.3)^{*}$ & $35.0(8.3)$ \\
\hline
\end{tabular}

Notes and abbreviations: ${ }^{*} \mathrm{P}<0.001 ;{ }^{* *} \mathrm{P}<0.01 ;{ }^{* * *} \mathrm{P}<0.05$; Blanks in table indicate a non significant $\mathrm{P}$ value for the three scale in that test. ${ }^{1}$ only $9(4.5 \%)$ persons do physical activity regularly; diabetes $3(1.5 \%)$.

burnout dimensions was associated with a specific set of covariates. The sets of variables associated with EE and with DP were quite similar. Age and the number of years in practice were strongly positively associated $(\mathrm{r}=$ $0.785^{* *}, \mathrm{P}<0.001$ ) indicating that older nurses are also likely to be more experienced. The scores of EE increase according to age especially for 30 - 39 years age groups, and family situation (married subjects have higher EE scores than unmarried subjects). Depersonalization was highest among nurses in private sector (11.67 vs. 9.55; P $<0.05)$, and PA was highest among nurses in public sector $(36.12$ vs. $32.91 ; \mathrm{P}<0.05)$. DP proved to be higher in night and rotating shift nurses compared to daytime workers. The PA scores decrease in night and rotating shift nurses compared to daytime workers. Statistically significant relationships were found between health status and quality of life perception, job satisfaction, and burnout. Nurses who reported that they will leave work in their institution in 12 months reported high level of DP, and low levels of PA.

In multivariate analysis, a high score on the PA subscale was significantly associated with age, salary, and public hospitals. The positive ratings of job satisfaction predicted lower levels of emotional exhaustion, and DP and a high level of PA in the current job and workplace. The morbidity variables as depression, backache, and headache are predictors to burnout and were retained in the final model (Table 6).

\section{DISCUSSION AND CONCLUSION}

Burnout seems problematic for nurses whose mental health is very crucial to health related quality of life. The psychometric properties of the Arabic version of MBIHSS are similar to the original MBI [3]. The factorial analysis of the scales yielded identical results to the original version. Nevertheless, the item "I feel frustrated by my job", and "recipients blame him for some of their problems" did not load on the expected factors, leading the corresponding EE, and DP dimensions to be defined by only eight and four items respectively without losing much information [32]. Earlier research documented a problem with the 12th item (feels energetic) [33], and with the 16th item of the MBI-HSS [3,7]. The reliability of scale scores was acceptable, namely 0.70 or higher for group comparisons [30].

The findings from the present study support previous research suggesting that nurses are susceptible to burnout $[1,23,25,34]$. Our results provide strong evidence that older age and experience are important predictors of burnout. In contrast with our results, several studies had found that young nurses are most enthusiastic about nursing [25], and then are likely to fall prey to nursing burnout as a result of role conflict [18]. The disparity between government and private health care settings continues to be an issue of debate and warrants more in-depth investigation [1]. In our study, private employment sector was associated with lower scores of personal accomplishment, this is in contrast with results found in Palestinian nurses [1]. Also, the married nurse had more burnout, in contrast with other study reporting that single people were more prone to the appearance of burnout syndrome [35].

This study replicates other published data of the negative association between working shifts and burnout [18] [25], and more globally between job satisfaction and health [34,36]. Indeed, night and rotating (day/night) shifts not only adversely affect the DP, and PA of the nurses, but may also increase the risk of stress [25], unhealthy lifestyle, less time sleeping, cardiometabolic risk profile [36], and may explain the use of tranquilizers [3]. Therefore, considering the shift preferences for working schedules can help foster a working atmosphere characterized by caring, respect, warmth, and consideration. 
Table 6. Influence of gender and employment sector on the MBI-HSS scale scores: multivariate analysis results (generalized linear model).

\begin{tabular}{|c|c|c|c|c|c|c|c|c|c|}
\hline \multirow[b]{2}{*}{ Parameter } & \multicolumn{3}{|c|}{ Emotional exhaustion } & \multicolumn{3}{|c|}{ Depersonalization } & \multicolumn{3}{|c|}{ Personal accomplishment } \\
\hline & $\beta$ & SE & $\mathbf{P}$ & $\beta$ & SE & $\mathbf{P}$ & $\beta$ & SE & $\mathbf{P}$ \\
\hline Habitat (urban vs. rural) & 0.81 & 1.41 & 0.57 & -0.02 & 0.95 & 0.98 & -0.78 & 1.27 & 0.54 \\
\hline Gender (male vs. female) & -3.00 & 1.70 & 0.08 & 1.23 & 1.14 & 0.28 & 1.61 & 1.53 & 0.29 \\
\hline \multicolumn{10}{|l|}{ Age (years) } \\
\hline $20-29$ vs. 30 and plus & -1.13 & 1.52 & 0.58 & 0.31 & 1.01 & 0.76 & -3.55 & 1.36 & 0.01 \\
\hline Nationality (lebanese yes vs. no) & -3.27 & 2.54 & 0.20 & -0.21 & 1.71 & 0.90 & -0.27 & 2.29 & 0.91 \\
\hline Employment sector (private vs. public) & -0.59 & 1.54 & 0.70 & 1.92 & 1.04 & 0.07 & -3.42 & 1.39 & 0.01 \\
\hline Nurse vs. HN/supervisor & -3.70 & 2.76 & 0.18 & 0.61 & 1.85 & 0.74 & -1.29 & 2.49 & 0.60 \\
\hline RN vs. HN/supervisor & 2.43 & 2.42 & 0.32 & -1.33 & 1.62 & 0.41 & -0.08 & 2.18 & 0.97 \\
\hline Salary & 0.00 & 0.00 & 0.52 & 0.00 & 0.00 & 0.16 & 0.006 & 0.003 & 0.04 \\
\hline Work overload (yes vs. no) & 6.86 & 2.44 & 0.005 & 1.67 & 1.64 & 0.31 & -4.22 & 2.20 & 0.05 \\
\hline \multicolumn{10}{|l|}{ Shift duty } \\
\hline Day vs. Alternant & -0.78 & 1.68 & 0.64 & -2.24 & 1.13 & 0.05 & 3.32 & 1.52 & 0.03 \\
\hline Night vs. Alternant & 1.17 & 2.22 & 0.60 & 1.11 & 1.49 & 0.46 & -0.73 & 2.00 & 0.71 \\
\hline Overtime (no vs. yes) & 0.79 & 1.42 & 0.58 & -0.13 & 0.96 & 0.89 & -0.17 & 1.28 & 0.90 \\
\hline \multicolumn{10}{|l|}{ Health status perception } \\
\hline poor vs. G \&VG & 2.57 & 3.33 & 0.44 & 2.97 & 2.23 & 0.19 & -3.64 & 3.00 & 0.23 \\
\hline Fair vs. G \&VG & 2.78 & 1.78 & 0.12 & 1.73 & 1.20 & 0.15 & -2.44 & 1.60 & 0.13 \\
\hline \multicolumn{10}{|l|}{ QOL perception } \\
\hline Very poor \& poor vs. G \&VG & -4.56 & 5.00 & 0.36 & -4.64 & 3.36 & 0.17 & -2.14 & 4.50 & 0.64 \\
\hline Intermediate vs. G \&VG & 0.49 & 1.75 & 0.78 & -0.49 & 1.17 & 0.68 & -0.56 & 1.58 & 0.72 \\
\hline \multicolumn{10}{|l|}{ Satisfaction with work } \\
\hline Very poor $\&$ poor & 7.30 & 2.38 & 0.003 & 4.97 & 1.60 & 0.002 & -3.71 & 2.15 & 0.09 \\
\hline Intermediate/G \&VG & 3.35 & 1.70 & 0.05 & 1.72 & 1.14 & 0.13 & -2.23 & 1.53 & 0.15 \\
\hline Smoking (yes vs. no) & 0.80 & 1.50 & 0.60 & 0.07 & 1.01 & 0.95 & -0.85 & 1.35 & 0.53 \\
\hline Physical activity (leisure) & 1.20 & 1.55 & 0.44 & -0.84 & 1.04 & 0.42 & 0.57 & 1.40 & 0.69 \\
\hline Depression (yes vs. no) & 4.27 & 1.89 & 0.03 & 3.67 & 1.27 & 0.004 & 1.77 & 1.70 & 0.30 \\
\hline Backache (yes vs. no) & 4.85 & 1.50 & 0.002 & 0.52 & 1.01 & 0.60 & 0.04 & 1.35 & 0.80 \\
\hline Headache (yes vs. no) & 2.91 & 1.59 & 0.07 & 4.72 & 1.07 & 0.000 & -2.07 & 1.43 & 0.15 \\
\hline Hypertension (yes vs. no) & 2.54 & 3.22 & 0.43 & 0.58 & 2.16 & 0.79 & -4.08 & 2.90 & 0.16 \\
\hline R square & & $40.1 \%$ & & & $39.7 \%$ & & & $25.5 \%$ & \\
\hline
\end{tabular}

Notes and abbreviations: $\mathrm{SE}=$ standard error; $\mathrm{P}=\mathrm{P}$ value; $\mathrm{RN}=$ registered nurse; $\mathrm{HN}=$ head nurse; $\mathrm{G} \& \mathrm{VG}=$ good $\&$ very good; $\mathrm{QOL}=\mathrm{quality}$ of Life. 
Managers should encourage towards the idea of "lifework balance" not "work-life balance" (i.e. life in first) [18]. Our findings are in accordance with previous studies which concluded that depressive symptoms mediated all scales scores of MBI-HSS which could be at the origin of somatic and psychological disorders [22,23,37].

One of the limitations of this study is the sample size. While it was adequate for this analysis, it is insufficient to allow for a more detailed analysis of differences in workplace and burnout across different hospitals' departments. This study is limited to South Lebanon because of a lack of resources and time. It is a cross sectional study. A causal relationship between burnout and predictors cannot be established. Finally, the absence of another valid reference instrument in Arabic remains a major obstacle for the establishment of concurrent validity as well as predictive validity $[30,38]$.

In conclusion, the main psychometric properties of reliability and validity of the Arabic version of MBI-HSS appear to be satisfactory, they are similar to the version in US. [3] and it is possible to use this instrument for burnout assessment in Lebanon. This study presents strong evidence that many nurses experience mental health disturbances. It is therefore in the interest of employers, governments and policy makers to reduce emotional exhaustion [6,9], promote employee mental health and well-being [10,39], improve quality of life [30], and increase motivation to work [40]. The development of an administrative strategy which, will contribute to the early detection, reduction, and prevention of nursing burnout in Lebanon is a priority.

\section{REFERENCES}

[1] Abushaikha, L. and Saca-Hazboun, H. (2009) Job satisfaction and burnout among Palestinian nurses. Eastern Mediterranean Health Journal, 15, 190-197.

[2] Spoor, E., de Jonge, J. and Hamers, J.P.H. (2010) Design of the DIRECT-project: Interventions to increase job resources and recovery opportunities to improve jobrelated health, well-being, and performance outcomes in nursing homes. BMC Public Health, 10, 293. doi:10.1186/1471-2458-10-293

[3] Maslach, C., Jackson, S.E., Leiter, M.P., Schaufeli, W.B. and Schwab R.L. (1986) Maslach burnout inventory sampler set manual, general survey, human services survey, educators survey, \& scoring guides. Mind Garden Publishers, Menlo Park. http://www.mindgarden.com

[4] Marin, M. and Campayo, G.A. (2010) A newer and broader definition of burnout: Validation of the "burnout clinical subtype questionnaire (BCSQ-36). BMC Public Health, 10, 302. http://www.biomedcentral.com/1471-2458/10/302

[5] Gulalp, B., Karcioglu, O., Sari, A. and Koseoglu, Z. (2008) Burnout: Need help? Journal of Occupational Medicine and Toxicology, 3, 32 .

\section{doi:10.1186/1745-6673-3-32}

[6] Landa, J.M.A. and López-Zafra, E. (2010) The impact of emotional intelligence on nursing: An overview. Psychology, 1, 50-58.http://www.SciRP.org/journal/psych

[7] Galanakis, M. (2009) Factorial structure and psychometric properties of the maslach burnout inventory (MBI) in Greek midwives. Europe's Journal of Psychology, 4, 52-70. http://www.ejop.org

[8] Vercambre, M.N., Brosselin, P., Gilbert, F., Nerrière, E. and Kovess-Masféty, V. (2009) Individual and contextual covariates of burnout: A cross-sectional nationwide study of French teachers. BMC Public Health, 9, 333. doi:10.1186/1471-2458-9-333

[9] Hilton, M.F. and Whiteford, H.A. (2010) Interacting with the public as a risk factor for employee psychological distress. BMC Public Health, 10, 435. doi:10.1186/1471-2458-10-435

[10] Canouï, P. and Mauranges, A. (2008) Le burn out a l'hopital. Le syndrome d'epuisement professionnel des soignants. 4th Edition, Elsevier Masson SAS, Paris.

[11] Lauvrud, C., Nonstad, K. and Palmstierna, T. (2009) Occurrence of post traumatic stress symptoms and their relationship to professional quality of life (ProQoL) in nursing staff at a forensic psychiatric security unit: A crosssectional study. Health and Quality of Life Outcomes, 7, 31. doi:10.1186/1477-7525-7-31

[12] Maslach, C., Jackson, S.E., Leiter, M.P., Schaufeli, W.B. and Schwab, R.L. (1986) Maslach burnout inventory instruments and scoring guides forms: General, human services, \& educators. Health and Quality of life Outcomes, 7, 31. http://www.mindgarden.com

[13] Montero-Marín, J., García-Campayo, J., Mera, D.M. and. del Hoyo, Y.L. (2009) A new definition of burnout syndrome based on Farber's proposal. Journal of Occupational Medicine and Toxicology, 4, 31 . doi:10.1186/1745-6673-4-31

[14] Quenot, J.P., Rigaud, J.P., Prin, S., Barbar, S., Pavon, A. and Hamet, M. (2012) Suffering among carers working in critical care can be reduced by an intensive. Intensive Care Medine, 38, 55-61.

[15] Lundgren-Nilsson, A., Jonsdottir, I.H., Pallant, J., Ahlborg Jr., G. (2012) Internal construct validity of the shirom-melamed burnout questionnaire (SMBQ). BMC Public Health, 12, 1. doi:10.1186/1471-2458-12-1

[16] Karlson, B., Jönsson, P., Pölsson, B., Åbjörnsson, G., Malmberg, B., Larsson, B. and Österberg, K. (2010) Returnrto work after a workplace-oriented intervention for patients on sick-leave for burnout a prospective controlled study. BMC Public Health, 10, 301. http://www.biomedcentral.com/1471-2458/10/301.

[17] Makary, M., Sexton, J., Syin, D., Feischlag, J., Holzmueller, C., Millman, A., Rowen, L. and Pronovost, P. (2006) Operating room teamwork among physicians and nurses: Teamwork in the eye of the beholder. Journal of American College of Surgeons, 202, 746-752. doi:10.1016/j.jamcollsurg.2006.01.017

[18] Lei, W., Hee, K.Y. and Dong, W. (2010) A review of research and strategies. British Journal of Nursing, 19, 
844-850.

[19] Bou Antoun, R. and Salameh, P. (2009) La satisfaction des pharmaciens au Liban et la perspective de la pharmacie clinique. Eastern Mediterranean Health Journal, 15, 15531563.

[20] Patrick, K. and Lavery, J.F. (2007) Burnout in nursing. Australian Journal of Advanced Nursing, 24, 43-48.

[21] Cunradi, C.B., Lipton, R. and Banerjee, A. (2007) Occupational correlates of smoking among urban transit operators: A prospective study. Substance Abuse Treatment, Prevention, and Policy, 2, 36. doi:10.1186/1747-597X-2-36

[22] Browning, L., Ryan, C.S., Thomas, S., Greenberg, M. and Rolniak, S. (2007) Nursing specialty and burnout. Psychology, Health \& Medicine, 12, 248-254. doi:10.1080/13548500600568290

[23] Moulou, A., Giotakis, K., Zoumakis, E. and Ilias, I. (2009) Alexithymia and its association with burnout, depression and family support among Greek nursing staff. Human Resources for Health, 7, 72 .

[24] Harwood, L., Ridley, J., Wilson, B. and Laschinger, H.K. (2010) Workplace empowerment and burnout in Canadian nephrology nurses. The CANNT Journal, 20, 12-17.

[25] Koivula, M., Paunonen, M. and Laippala P. (2000) Burnout among nursing staff in two Finnish hospitals. Journal of Nursing Management, 8, 149-158. doi:10.1046/j.1365-2834.2000.00167.x

[26] El-Jardali, F., Dumit, N., Jamal, D. and Mouro, G. (2008) Migration of Lebanese nurses: A questionnaire survey and secondary data analysis. International Journal of Nursing Studies, 45, 1490-1500. doi:10.1016/j.ijnurstu.2007.10.012

[27] Aylé, G.K. (2011). Empowering nursing role in decisionmaking. Medhealth, Beyrouth, Habtoor Hotel.

[28] Haroun, S. (2008) Nurses: The heartbeat of hospitals. American University of Beirut, Beirut. http://www.syndicateofhospitals.org.lb/publication/Nurse s\%20the $\% 20$ Heartbeat $\% 20$ of $\% 20$ Hospitals.pdf.

[29] El-Jardali, F., Dimassi, H., Dumit, N., Jamal, D. and Mouro, G. (2009) A national cross-sectional study on nurses' intent to leave and job satisfaction in Lebanon: Implications for policy and practice. BMC Nursing, 8, 3 . doi:10.1186/1472-6955-8-3

[30] Sabbah, I., Drouby, N., Sabbah, S., Retel-Rude, N. and
Mercier, M. (2003) Quality of Life in rural and urban populations in Lebanon using SF-36 Health Survey. Health and Quality of Life Outcomes, 1, 30. doi:10.1186/1477-7525-1-30

[31] Nunnally, J.C. and Bernstein, I.H. (1994) Psychometric theory. 3rd Edition, McGraw-Hill, New York, 1994.

[32] Mandhouj, O., Etter, J.-F., Courvoisier, D. and Aubin, H.-J. (2012). French-language version of the World Health Organization quality of life. Health and Quality of Life Outcomes, 10, 39. doi:10.1186/1477-7525-10-39

[33] Önder, C. and Basim, N. (2008) Examination of developmental models of occupational burnout using burnout profiles of nurses. Journal of Advanced Nursing, 64, 514-523. doi:10.1111/j.1365-2648.2008.04818.x

[34] Bogaert, P.V., Clarke, S., Roelant, E., Meulemans, H. and Van de Heyning, P. (2009) Impacts of unit-level nurse practice environment and burnout on nurse-reported outcomes: A multilevel modelling approach. Journal of Clinical Nursing, 19, 1664-1674. doi:10.1111/j.1365-2702.2009.03128.x

[35] Landa, J. and López-Zafra, E. (2010) The impact of emotional intelligence on nursing: An overview. Psychology, 1, 50-58. doi:10.4236/psych.2010.11008

[36] Jermendy, G., Nadas, J., Hegyi, I., Vasas, I. and Hidvegi, T. (2012) Assessment of cardiometabolic risk among shift workers in Hungary. Health and Quality of Life Outcomes, 10, 18. doi:10.1186/1477-7525-10-18

[37] Sabbah, I., Vuitton, D.-A., Droubi, N., Sabbah, S. and Mercier, M. (2007) Morbidity and associated factors in rural and urban populations of South Lebanon: A crosssectional community-based study of self-reported health in 2000. Tropical Medicine and International Health, 12 907-919. doi:10.1111/i.1365-3156.2007.01886.x

[38] Bollinger, M., Power, M.J., Aaronson, N.K., Cella, D.F. and Anderson, R.T. (1996) Creating and evaluating crosscultual instruments. In: Spilker, B., Ed., Quality of Life and Pharmacoecoeconomics in Clinical Trials, 2nd Edition, Lippincott-Raven Publishers, Philadelphia, 659-668.

[39] Helkavaara, M., Saastamoinen, P. and Lahelma, E. (2011) Psychosocial work environment and emotional. $B M C$ Research Notes, 4, 101. doi:10.1186/1756-0500-4-101

[40] Pape, H.-C. and Pfeifer, R. (2009) Restricted duty hours for surgeons and impact on residents quality. Patient Safety in Surgery, 3, 3. http://www.pssjournal.com/content/3/1/3 